\title{
A mamãe e a prostituta Os homens, as mulheres e o rugby
}

Anne Saouter**

Resumo: identificando o mundo do rugby como um universo cultural que vai além de ser apenas uma atividade de lazer vinculada à aprendizagem das técnicas do jogo, o trabalho busca compreender aspectos do complexo processo de socialização no qual estão inseridos aqueles que fazem parte da família rugby. Dando atenção especial ao terceiro tempo e às atividades que ocorrem fora do campo de jogo, procura-se compreender o espírito do rugby, em particular no que se refere às relações que os jogadores (homens) estabelecem com as mulheres durante toda a sua carreira.

Palavras-chave: Cultura, Esporte, Rugby, Gênero.

O rugby é um esporte conhecido principalmente pela dureza de seu jogo e pelo físico às vezes impressionante de seus jogadores. Fora do estádio, os rugbymen são conhecidos por sua convivialidade e gostam de se encontrar em famigeradas festas das quais se sabe apenas o nome: os terceiros tempos. Elas reúnem os jogadores das equipes que acabaram de se enfrentar, em torno de um balcão de bar ou de uma mesa de restaurante, e terminam nas casas noturnas. Lá bebem muito, riem, choram cantam...

A trilogia, que são as duas seqüências da partida e seu terceiro tempo, parece ser uma particularidade do rugby por seu caráter quase institucional. "Não existe rugby sem terceiro tempo", dizem muitos jogadores. Mas, também poderíamos acrescentar, não existem mulheres nos terceiros tempos. É um fato evidente, o rugby é um esporte que se enuncia somente no masculino, pelo menos é o que afirma a maioria dos rugbymen. É "um assunto de homens" que não diz respeito às mulheres, sobretudo durante o terceiro tempo. O discurso de exclusão pode até mesmo ser acompanhado de um sentimento de medo: "Elas nos vigiam", "Elas correm o risco de estragar tudo", "Elas sem-

\footnotetext{
* Agradeço a Jean-Pierre Albert por sua leitura atenta e seus preciosos conselhos.
}

** Centro de Antropologia, Toulouse.

Movimento, Porto Alegre, v. 9, n. 2, p. 37-52, maio/agosto de 2003 
pre são espalhafatosas"... ${ }^{1}$ Mas será que o rugby, esporte da virilidade por excelência no imaginário coletivo, não exigiria obrigatoriamente um reflexo externo para validar essa virilidade: o olhar das mulheres? Afinal, qual é a razão de ser viril se não é para o sexo oposto?

A imprensa e a literatura difundem amplamente a tradição machista do rugby: os inúmeros livros ou artigos da imprensa dedicados ao esporte nunca mencionam as mulheres ou mencionam muito pouco. No entanto, a imagem da família é constantemente explorada nas narrativas escritas e orais. "O rugby é uma grande família" é uma frase enunciada sempre. Seria então uma família unicamente composta por homens?

Vamos esquecer os preconceitos e ser mais atentos. As mulheres estão bem presentes nos estádios durante as partidas. Sentadas nas arquibancadas, algumas se limitam a um papel de "torcedora" discreta, outras riem, gritam, insultam. Depois da partida, elas se encontram em grupo diante dos vestiários e discutem entre si, esperando a saída dos jogadores. Algumas acompanham os homens ao bar do clube (o "club house") para festejar a vitória ou consolar a derrota; outras vão embora nesse momento; e outras, por fim, são admitidas no cenáculo viril do terceiro tempo. Quem são elas? O que fazem? Ao segui-las, rapidamente entendemos que seus percursos no mundo dos homens não devem nada ao acaso: conforme são mães de jogadores, esposas ou "groupies", as mulheres têm lugares bem diferentes na "família rugby". Não seriam definidos os lugares em relação às exigências que determinam a vida esportiva do rugbyman? Para responder a esta pergunta, seria útil analisar primeiro a maneira com que se realiza a integração do jogador nessa família singular.

\section{"Ser rugby"}

"Ele saiu como uma bola de rugby!" Esta comparação é uma forma muito curiosa de descrever a maternidade. Sem dúvida, a mãe que fala nestes termos sobre seu parto deve ter saído de uma região "rugbística" e a frase deixa prever o futuro do re-

1 Todas os depoimentos citados foram coletados junto aos rugbymen e às mulheres do rugby. Fiz minhas pesquisas junto a várias equipes da região bordelesa, dos clubes de primeira divisão às séries menores.

Movimento Porto Alegre, v. 09, n. 2, p. 37-52, maio/agosto de 2003 
cém-nascido, saído do ventre como uma bola expulsa de um scrum. Se, no entanto, o acaso tiver atribuído virilidade a ele... Trabalhando no percurso biográfico dos rugbymen, interessei-me sobretudo pelas expressões menos metafóricas de seu começo: por que haviam escolhido o rugby? Os primeiros que interroguei freqüentemente faziam referência a um membro de sua família, antigo rugbyman, para contar a gênese de sua paixão. Essa razão de "hereditariedade" me fez levantar sistematicamente a seguinte questão: "Você tem um ou mais rugbymen na família?"²

Os jogadores, em sua grande maioria, responderam positivamente e pareciam dar muita importância a esse detalhe. Tanto é que uma ausência de filiação direta, que ligasse o indivíduo desde o nascimento à "família rugby", induzia um discurso particular: a busca de uma filiação "arranjada" (longínqua ou fictícia) que convencia o sujeito de sua posição de herdeiro.

O caso mais comum é o invariável "tal pai, tal filho". O futuro rugbyman nasce de um pai rugbyman. Senão, muitas vezes é à mãe que cabe uma parte da responsabilidade: "O pai da minha mãe jogava rugby". Tal atavismo às vezes é relatado no espírito dos lugares, especialmente no país basco, uma região onde pelota basca, jogo de força basca ${ }^{3}$ e rugby se conjugam facilmente: "Meu pai não é nada esportivo, mas minha mãe é basca. Por isso, fui levado ao rugby." "Meu pai não era um rugbyman; em contrapartida, sou basco. Está meio inscrito nos genes."

O que acontece com aqueles que não têm pai rugbyman nem mãe basca ou nem descendem de um jogador? Esses "órfãos" são, em geral, nativos de regiões onde o rugby tem pouco espaço na cultura local (ao contrário do Grande Sudoeste). ${ }^{4}$ Basta-lhes, às vezes, tornar a montar a árvore genealógica para descobrir, com um alívio inadmitido, que um de seus ancestrais já fora da grande família: "Sou do Jura, minha mulher também. Mas descobri que meu bisavô jogava rugby."

O último caso que encontrei foi o da "geração espontânea". $\mathrm{Na}$ falta de uma justificativa familiar ou geográfica para valori-

2 Fiz a pergunta no decorrer de 30 entrevistas individuais ou durante encontros, informais e muito numerosos, em situação de observação participante: partidas, encontros esportivos amigáveis, refeições e terceiros tempos.

3 (N. do T.) No qual se disputa a força física.

4 Regiões basca, occitânica e catalã.

Movimento, Porto Alegre, v. 9, n. 2, p. 37-52, maio/agosto de 2003 
zar, os rugbymen se referem a um traço de sua personalidade ou a uma característica física: "Quando eu era pequeno, morava em Paris. Eu era grandalhão. Jogava futebol, mas eu era muito ruim. E depois, o instrutor, originário de Narbonne, quis criar uma seção de rugby na escola. Ele começava bem, já tinha um grandalhão." "Comecei pelo futebol. No Jura, região do futebol! Mas eu era viril demais, sempre era suspenso. Dava golpes proibidos no futebol que não o são no rugby. Depois, cheguei na região, em Hourtin, com o exército. Encontrei rugbymen que me fizeram vir a Bègles."

Em suma, uma conversão à "bola oval" ainda é coisa do destino: decididamente, a "bola redonda" não lhes convinha.

Esses testemunhos são suficientes para salientar uma primeira característica do mundo da bola oval: longe de ser apresentada como simples escolha de um lazer, a prática do rugby se torna um traço essencial da identidade da pessoa. De fato, quando não é natural, a plena pertença a esse universo decorre de um complexo processo de socialização, que ultrapassa a simples aprendizagem técnica do jogo.

Os inúmeros jogadores que tinham um pai rugbyman puderam, desde a menor idade, familiarizar-se com a estranha bola. É, com efeito, após o nascimento do filho que o pai compra uma. Antes disso, ele não a possui, exceto talvez, exposta numa vitrine ou relegada ao fundo da garagem, uma bola de colecionador coberta de assinaturas, lembrança da última partida jogada, da última Copa do Mundo... Inútil ter uma bola em casa, afinal, no rugby, o envolvimento é apenas coletivo: a bola oval dificilmente serve para manipulações solitárias, é preciso ter pelo menos dois para "dar vida". A bola faz, portanto, a sua aparição no lar quando este cresce e permite rapidamente uma relação privilegiada entre pai e filho. O pai transmite ao seu descendente os gestos elementares do jogo - o drop kick, o passe para trás, etc. e, evidentemente, prepara o futuro: "Meu filho fará o que quiser. Mas eu preferiria que ele jogasse rugby".

O menino, é claro, está livre para escolher, já que o rugby não escapa ao eventual desejo de emancipação ou de contradição da autoridade paterna. E, no entanto, muitas vezes aparece como um destino incontornável. Sem mencionar que se entra no rugby assim como se entra numa religião, é necessário reconhecer que normalmente se trata de um comprometimento duradouro, até mesmo definitivo, quase uma escolha de vida. Ao 
desejar que seu filho jogue rugby, o pai entende estar lhe transmitindo todo um sistema de valores e, para fazer dele, em suma, o seu "verdadeiro" filho, ele deve confiar a sua formação a uma outra "família" que não a sua: a do clube e de seus principais elementos - treinadores, dirigentes e colegas de equipe.

As singularidades dessa formação se devem, em larga medida, à própria natureza do jogo: um jogo complexo, mas sobretudo "duro" e "viril", que requer qualidades morais - coragem, espírito de equipe ou mesmo de sacrifício (além da dor real, os rugbymen estão conscientes de que "acabarão mal": seqüelas de antigos ferimentos, artrose, etc.) - tanto quanto competências técnicas ou táticas. A permanência do contato com os parceiros e adversários (durante os agrupamentos, os scrums, as laterais e os tackles) impõe que o jogador vença o seu medo do confronto físico bem como os tabus ligados à intimidade corporal: toco o outro, sou tocado por ele. Isso implica, de um lado, uma aceitação e, ao mesmo tempo, um domínio da violência na relação com os adversários e, por outro lado, uma neutralização do significado erótico do contato físico entre parceiros.

Podemos levantar a hipótese de que a formação do jogador está centrada na produção dessa relação muito particular com o corpo e que isso reage na totalidade do "espírito rugby", entre outras coisas, na administração das relações com o outro sexo. Como veremos, as exigências desse programa não coincidem exatamente - tanto em seu conteúdo como em sua cronologia com as exigências da formação habitual de um homem completo. A fim de esclarecer este fenômeno, vamos examinar a maneira com que se apresentam as relações do rugbyman com as mulheres ao longo de sua carreira.

\section{Histórias do esporte}

A primeira mulher presente na vida do jogador é evidentemente a mãe, que, como vimos, com freqüência é ela mesma filha ou esposa de um rugbyman. Enquanto o menino está sob sua proteção, é ela que o leva ao estádio para ver seu pai (ou alguém próximo) jogar. Ambos assistem ao mesmo espetáculo, mas cada um recebe uma mensagem diferente: ele vê um modelo a ser seguido, ela sente a futura partida de seu filho para um mundo de homens, brutal e talvez perigoso. "Se eu tiver um filho pilar que não seja agressivo nem briguento, tudo bem. Se

Movimento, Porto Alegre, v. 9, n. 2, p. 37-52, maio/agosto de 2003 
jogar atrás, melhor ainda." "Tenho medo, quando às vezes vejo o ódio dos jogadores, é muito violento (...) eu não quero que acabem com o meu menino."

Apesar desses temores, a presença da mãe nas arquibancadas prova a sua conivência. Ela legitima aos olhos de seu filho a existência de um grupo masculino ao qual ele será brevemente integrado. O aparecimento da bola no âmbito familiar será um primeiro sinal da separação entre o filho e a mãe. Mesmo que ela às vezes tente embaralhar as pistas: "Eu pedi à minha mulher para comprar uma bola com pontas. Ela trouxe uma bola de plástico qualquer, redonda!"

Quando uma criança começa a jogar, a mãe se encarrega da manutenção de seu equipamento, e isso permanece verdadeiro por tanto tempo quanto o jogador residir na casa da família: mesmo que ela não vá vê-lo jogar, essa é a sua contribuição mínima para a atividade de rugby de seu filho, também o sinal de seu consentimento a essa carreira perigosa. Em seguida, na ocasião de cada partida, o grupo dos homens se encarrega do jogador. Antes mesmo de se afirmar no terreno, este comporta uma etapa de separação exacerbada com o outro sexo: a passagem pelos vestiários. ${ }^{5}$ Os rugbymen mantêm um verdadeiro mistério em torno desse primeiro momento. Uma mulher, em princípio, nunca saberá o que acontece lá, pois o acesso lhe é proibido (exceto, há pouco tempo, aos raros "auxiliares técnicos" do sexo feminino). De fora, ela perceberá apenas o barulho das travas das chuteiras no ladrilho e um forte odor de cânfora. Eu não fugi à regra; por várias vezes um jogador, aliás muito bem disposto a favorecer minhas pesquisas, me lembrou dessa proibição: “É uma pena, pois seria muito interessante para você, há um lugar onde você nunca poderá entrar: os vestiários."

As razões desse veto são, em geral, de ordem técnica: os jogadores devem "se concentrar", ouvir os últimos conselhos do treinador e, principalmente, sermões muitas vezes violentos destinados a "motivá-los". Isso é acompanhado de fórmulas singulares de aquecimento: os pilares, que freqüentemente reproduzem no espaço dos vestiários a sua posição no scrum, se empurram, ombro contra ombro, passam seus braços em volta das costas do vizinho. É restabelecido o "coletivo" em sua dimensão mais carnal. E, para que cada jogador produza em si mesmo o

5 Sobre a questão dos ritos de separação, cf. Godelier (1982).

Movimento Porto Alegre, v. 09, n. 2, p. 37-52, maio/agosto de 2003 
corpo que se tornará parte do corpo coletivo da equipe, é preciso marcar uma ruptura com o universo feminino. Essa ruptura já terá se traduzido, na véspera da partida, por uma abstinência sexual que é encontrada também entre os toureiros. Aconselhada há muito tempo pelos treinadores, a abstinência é cada vez menos respeitada, mas mesmo assim ouve-se com freqüência: "É melhor quando não estamos com as mulheres um ou dois dias antes" (principalmente das partidas importantes).

Uma vez que os homens tiverem se encontrado assim, o jogo pode começar. Eles irão defender as cores do clube, "suar a camisa", símbolo concreto de sua pertença comum. O que as mulheres estão fazendo neste momento? As esposas dos jogadores, quando se deslocam para ver seus maridos jogar, geralmente têm seu lugar reservado nas arquibancadas. Porém, ao contrário do grupo das mães, também muito bem representadas, elas são convidadas a uma certa discrição. As mães, por sua vez, são autorizadas pelo costume a certos excessos verbais ou comportamentais: insultos ao árbitro, golpes de guarda-chuva que se tornaram lendários em todos os times, xingar um jogador que estiver ameaçando seu "garotão"...

Terminada a partida, os jogadores passam novamente pelo crivo dos vestiários para tirar as marcas do rugby: curam-se as feridas, limpa-se a lama e o sangue, faz-se a barba que havia sido mantida para o "influxo nervoso", recolocam-se as correntes e as alianças. Todos se preocupam com sua aparência. "Eles são piores que as patricinhas, ficam se olhando no espelho e não podem nem esquecer a correntinha! Preocupam-se muito com o seu look." "Essa espécie de negligência viril em relação ao seu físico é, de fato, enganosa. Meu marido passa mais tempo do que eu no banheiro. Ele anda por todos os lugares com o seu pente na mão."

Porém, essa metamorfose deixa um resíduo: a roupa suja. Quem vai lavá-la? Sabemos que a lavagem da roupa, em nossa cultura, é uma tarefa quase exclusivamente feminina que diz respeito à esfera da intimidade - a expressão "lavar a roupa suja em casa" não é uma metáfora sem fundamento. Portanto, é com uma mulher que o rugbyman estabelecerá inevitavelmente uma "relação de lavagem de roupa". Mas qual mulher? Quase todos os jogadores me disseram que reservavam às suas mães a lavagem das roupas, mesmo depois do casamento, ${ }^{6}$ se ao menos a

6 É sobretudo verdadeiro agora quanto aos assuntos de treinamento; os clubes estão se encarregando cada vez mais das camisas oficiais de partida.

Movimento, Porto Alegre, v. 9, n. 2, p. 37-52, maio/agosto de 2003 
distância permitisse. Será que o vínculo maternal, que parecia ter sido cortado pela bola, seria restabelecido pela camisa? $\mathrm{Na}$ verdade, podemos questionar se ele foi realmente rompido pela integração do menino ao mundo do rugby. ${ }^{7} \mathrm{~A}$ imagem do jogador que retorna à casa da mãe com suas coisas sujas lembra a do menino voltando da escola imundo depois de ter jogado no campo com seus colegas. E é perturbador que esse vínculo mãefilho, com tudo o que traz de reprovação e cumplicidade, permaneça após o casamento a despeito da passagem bíblica "o homem deixará pai e mãe e se unirá à sua mulher, e eles se tornarão uma só carne" (Gênesis, 2:24).

Simetricamente, as esposas do jogadores se recusam com freqüência a se ocupar da lavagem da roupa do rugby. Toda vez que eu perguntava a este respeito, elas me respondiam energicamente: "Ele assume"; "Ele quis jogar rugby, ele que se vire." Seguiam-se muitas vezes expressões de desgosto: é uma roupa muito suja, que fede muito. Quando a mãe não lava, o consenso se faz graças à máquina de lavar roupa. O marido deve ele mesmo colocar suas coisas na máquina ou, na melhor das hipóteses, no "cesto do rugby", e a esposa aceita depois estender a roupa e passála. Ela toca na roupa apenas quando está limpa, quando não traz mais os vestígios do rugby. Uma sacola não esvaziada pelo marido pode acabar do lado de fora da casa, de quarentena...

Essas manifestações de repulsa não estariam, no fundo, traduzindo a exterioridade mútua do rugby e da esfera conjugal? O que não passa de um sintoma nesses assuntos de roupa talvez revele uma partilha simbólica muito mais essencial: ligada pelas necessidades do jogo a um grupo exclusivamente masculino e chamado a fazer valer todas as suas qualidades "viris", não estaria o rugbyman fora de uma vida de adulto completo, não estaria conservando, mesmo casado, uma posição de adolescente "curtindo a juventude"?

\section{O eterno rapaz}

No Sudoeste, as mulheres dos rugbymen são chamadas de "viúvas do rugby". Isso designa bem os "sacrifícios" esperados das esposas: o rugby requer muita disponibilidade do marido, retido pelas partidas, treinamentos... e terceiros tempos. De acor-

7 Sobre a questão da roupa, cf. Kaufmann (1992).

Movimento Porto Alegre, v. 09, n. 2, p. 37-52, maio/agosto de 2003 
do com alguns, apenas mulheres familiarizadas desde a infância com a cultura do rugby podem entender e suportar. O casamento no mundo do rugby é, aliás, relativamente endógamo, já que os jogadores casam com freqüência as irmãs ou primas com outros jogadores. Mas talvez seja preciso também levar essa expressão "viúvas do rugby" ao pé-da-letra, ou quase: uma mulher de jogador perde o seu marido assim que ele entra no mundo do rugby.

Não se explica muita coisa atribuindo essa atitude com as esposas ao "machismo" do meio do rugby. O problema está, antes, em compreender por que, exatamente, o rugby leva ao extremo comportamentos coletivos que existem também, mas em grau menor, nos outros esportes de equipe masculinos. A este respeito, convém examinar o momento em que, junto com os vestiários, desempenha-se a exclusão mais forte em relação às mulheres e, mais precisamente, às esposas: o terceiro tempo.

Lembrei, no início deste estudo, as observações ouvidas com freqüência afirmando que as mulheres, se fossem admitidas na festa dos homens, "estragariam tudo" ou "seriam espalhafatosas". Trata-se, de fato, de repetir e sacralizar, fora do terreno, o corpo coletivo da equipe. A refeição em comum, a embriaguez compartilhada, as piadas escatológicas, os "strip teases" dos jogadores vêm lembrar a necessária liberdade desses corpos de rapazes dedicados a se misturar e sofrer juntos. Mesmo tendo parado de jogar, os homens do rugby mantêm entre si uma amizade muito carnal: beijam-se quando se encontram, abraçamse. A reflexão de um antigo jogador ilustra bem esse propósito: "No início, com meus colegas de trabalho, eu fazia como com os amigos do rugby. Eu falava com eles pegando-os pelos ombros ou pelos braços. Logo entendi que isso não era apreciado!"

Esse traços bem conhecidos do "folclore" do rugby, muitas vezes interpretados em termos de homossexualidade reprimida, podem, a meu ver, ser compreendidos como implicações necessárias de um jogo de contato que requer uma equipe realmente unida. As disposições requeridas para ser um bom jogador são assim simultaneamente formadas e experimentadas numa experiência de engajamento físico vivido em outros registros além do esporte; em particular, o da alimentação e o da sexualidade (Fabre, 1980 e 1986). Ora - e esse pode ser o nó da questão -, o programa formador do rugby coincide, neste aspec-

Movimento, Porto Alegre, v. 9, n. 2, p. 37-52, maio/agosto de 2003 
to, com o da iniciação habitual dos meninos, na Europa e em outros lugares (Maffesoli, 1985).

Para explorar apenas o registro da sexualidade, vamos examinar uma nova categoria de mulheres encontrada nas margens do mundo do rugby: as "groupies". Diferentemente das esposas, elas podem estar presentes na festa, podem beber, falar de rugby. Pouco importa, estão lá apenas para um jogo sexual lascivo. Elas especulam sobre a virilidade dos rugbymen, eles sobre a sexualidade sem tabu que supõem delas e, de fato, lhes impõem. Elas servem para o jogo, em particular, aceitando circular de um jogador a outro e se oferecerem sucessivamente a vários. Após o jogo coletivo em torno da bola, os jogadores se deleitam, assim, em ter a mesma parceira e, neste caso, chamam-se entre si de "cunhados". As groupies são pouco respeitadas tanto na ação como na fala. A elas, são dados apelidos insultantes: "Armadilha de Aids", "Campainha" (porque basta bater à sua porta para que ela se abra). E, de fato, elas não são destinadas a entrar em relações amorosas, mas existem somente na relação com o grupo em seu todo.

Outra prática encontrada em vários clubes: a "caixinha". Ela se refere mais particularmente à categoria dos mais novos e mostra em qual ponto a iniciação dos meninos é assumida de maneira quase institucional pelo grupo: durante a refeição em comum do terceiro tempo, cada jogador coloca uma soma de dinheiro numa caixa comum, bem como um pedaço de papel com o seu nome. O sorteio designa o adolescente que leva o montante, destinado a pagar uma prostituta. A relação sexual é vivida na intimidade, mas o ganhador deverá contar aos outros depois, que o aguardam. O grupo pode anular discretamente a parte do acaso do ritual arranjando para que apareça, por exemplo, o nome do mais tímido: maneira um pouco brutal de garantir que ele compartilhe com todo o grupo um mesmo grau de iniciação.

Tais costumes mostram a capacidade do rugby de assegurar, sob formas muito tradicionais, a formação dos jovens machos. Isso raramente apresenta dificuldades, já que se trata de solteiros. Mas o rugby, pelo menos nos estágios mais elevados da competição, não é especialmente um esporte de jovens: excelentes jogadores têm por volta de 30 anos, e às vezes mais. Portanto, não é raro que uma equipe contabilize uma boa parte de homens casados. Será que devem escolher entre a esposa e o 
grupo festivo? O fato é que, salvo raras exceções, são as esposas que se submetem à necessária solidariedade dos jogadores. Se a sua exclusão não é abertamente estabelecida em princípio, o código de conduta desejado lhes é imposto de maneira implícita: um olhar reprovador ou uma gozação indireta por parte do grupo sabem rapidamente redefinir os limites que não devem ser ultrapassados. As próprias mulheres interiorizaram a imagem desvalorizada da esposa desobediente. Conheço apenas um exemplo de mulher que recusa a lei do grupo acompanhando o seu marido no terceiro tempo e bebendo junto com os homens. Ela se diz voluntariamente provocadora, mas, ao mesmo tempo, ela assume com dificuldade essa transgressão ao pontuar o seu discurso com a justificativa "sempre tive trejeitos de menino" e ficando chocada por algumas cenas às quais assiste durante as festas. Paralelamente, ela é severamente julgada pelos outros, inclusive seu marido. Esse contra-exemplo confirma a regra; o vínculo social que une o grupo está, nesse ponto, presente nas consciências, tendo por efeito a marginalização de seus contestadores. ${ }^{8}$ Essa pressão moral, válida também para as companheiras habituais dos jogadores, aumenta ainda mais quando a união é oficializada. Se uma concubina desfruta ainda de uma certa liberdade, uma esposa é enviada sem escalas ao estatuto tradicional de dona-de-casa.

Também está fora de questão comentar com o marido, diante de seus colegas de equipe, a partida que ele acaba de jogar. Enquanto o grupo estiver presente, o rugby é um assunto de homens. É na esfera privada, de volta ao ambiente conjugal, que a palavra da mulher tem um espaço de expressão. O jogador ouve os seus conselhos, deixa-se cuidar, consolar: é o repouso do guerreiro. Ela é esposa, mas também uma "segunda mãe": afaga o seu jogador machucado e perdoa os seus "afastamentos" no terceiro tempo. "É preciso que eles se divirtam entre si, é um meio de homens e eis que você tem que aceitar, após um tempo você acaba cedendo."

Ele não deseja ver este aspecto de sua existência interferir com sua "vida de menino". Também não deseja ver sua esposa ultrapassar a fronteira que a aproximaria do grupo masculino: para justificar a sua exclusão, alguns não hesitam em invocar o medo de ela se sentir mal depois de beber. Na realidade, isso subentende, sobretudo, que ela arriscaria cair na categoria das groupies.

8 A respeito da violência simbólica, cf. Bourdieu (1984).

Movimento, Porto Alegre, v. 9, n. 2, p. 37-52, maio/agosto de 2003 
Para não arriscar tal confusão, o jogador fala muito pouco de sua esposa aos colegas de equipe. Em contrapartida, ele contará suas aventuras com uma groupie. Se, por acaso, ainda solteiro, ele se apaixonar por ela, não poderá restabelecer a situação na frente do grupo a não ser por meio do casamento: “Um dia, um cara que jogava conosco nos anunciou que tinha encontrado uma dessas moças... uma bomba sexual! Cada vez que a encontrava, ele nos contava tudo em seguida. E depois, em um certo momento, ele parou de nos falar. Um mês depois, ele nos disse: "Eu me casei". Nunca mais se voltou a falar nela."

A oficialização da relação impõe, assim, o respeitoso silêncio que cerca a esfera conjugal. Ele simboliza também o reconhecimento pelos homens da passagem de um dos seus para uma nova classe de idade. O adolescente que fazia estardalhaço em torno de suas aventuras sexuais tornou-se um adulto de sexualidade doravante oculta. Mas resta ainda um problema: a esfera da conjugalidade permanece externa ao mundo do rugby que, em contrapartida, impõe ao jogador que quer estar plenamente integrado à sua equipe uma vida de eterno rapaz.

\section{Envelhecendo no rugby}

No entanto, existem figuras da conciliação, inserindo-se também na lógica de um programa. De fato, a integração do rugbyman na comunidade do rugby é efetiva durante toda a sua vida: ele atravessa as diversas classes de idade, marcadas pelas categorias da competição (mirim, infantil, juvenil, etc.), muda de estatuto pessoal, atinge a posição de veterano, de jogador antigo, às vezes, por fim, as posições de treinador ou dirigente de clube. Como novas etapas de sua biografia esportiva, elas lhe permitem conservar um lugar ativo de rugbyman, no sentido etimológico do termo: "homem do rugby". A diversidade desses empregos faz com que, a todo momento, as gerações se encontrem. Os velhos, detentores da memória do clube, contam aos mais jovens a saga dos ancestrais. Como ligação preciosa entre passado e presente, ${ }^{9}$ eles são os sábios do grupo. Aliás, encontra-se no terreno o personagem do Ancião. As equipes muitas vezes compreendem um jogador com mais idade que os outros, escolhido para moderar o ímpeto dos mais jovens e lhes levar os conhecimentos adquiridos em sua longa experiência.

9 Pouquíssimos clubes franceses, ao contrário de seus correspondentes ingleses, conservaram arquivos escritos. Apenas a literatura oral é garantia da memória coletiva.

Movimento Porto Alegre, v. 09, n. 2, p. 37-52, maio/agosto de 2003 
Uma mesma regulação se opera nas margens festivas da partida. O treinador, severo para com seus "pequenos" quando o jogo "degenera", manifesta sua autoridade em outras ocasiões: "Havia um jogador que não conseguia evitar as festas no fim de semana. Ele acabava envolvendo-se em brigas e chegava todo machucado. Um dia, o treinador não agüentou mais. Ele tinha um amigo policial e fez um acordo com ele para que desse batidas lá onde o jogador fazia festa. Ele o prendia e colocava-o atrás das grades por 24 horas. Depois, levava-o para a partida em plena forma".

Os excessos do terceiro tempo dão lugar a um jogo mais nuançado nas fronteiras da transgressão. Treinadores e dirigentes nem sempre participam das festas e outras comemorações (somente os árbitros se abstêm), avalizando, evidentemente, o seu necessário desenvolvimento. Porém, continuam sendo garantias de uma ordem na desordem: "Fizemos um terceiro tempo num restaurante onde as paredes estavam repletas de objetos de decoração. Divertimo-nos retirando-os discretamente e levando-os para casa por baixo do casaco. Às 2 horas da madrugada, o dono telefonou para o nosso treinador. Ele chamou todos nós no meio da noite com a ordem de recolocar tudo no lugar. Foi o que fizemos."

Esses homens entre si, mesmo unidos por valores compartilhados, não ocupam posições menos diferentes. Aos mais velhos, aos mais sérios, cabe organizar tacitamente a iniciação dos mais novos, conservando o benefício da festa e, principalmente, de uma ativação sempre reiterada das lembranças. ${ }^{10}$ As antigas narrativas de partidas e "porres" são como que fecundadas pelo presente, revivem sua juventude na medida de sua liberdade conservada, no mínimo por intermédio de outra pessoa.

Também são momentos em que o grupo constata o fato de que, para a maioria, essa juventude terminou, quando foram superadas as etapas do casamento e da paternidade. Os clubes prevêem, assim, tempos de agregação em que rugbymen, esposas e filhos se reúnem: árvores de Natal, banquetes ou viagens turísticas. Estão muito longe dos terceiros tempos e torna-se muito difícil diferenciar o espírito do rugby das outras festividades institucionais características da vida associativa. Esses tempos de encontro existem também fora da estrutura do clube por

10 A respeito do estado de congregação, cf. Durkheim (1985: 499).

Movimento, Porto Alegre, v. 9, n. 2, p. 37-52, maio/agosto de 2003 
meio de convites mútuos aos casamentos, aniversários, comunhões, etc. Aí se organizam com freqüência partidas de rugby entre homens e mulheres. O jogo fica insignificante, é voluntariamente suavizado para não brutalizar as mulheres. Transformado em misto, ele perde sua dimensão agonística para se transformar em uma espécie de rito comunial, mas nostálgico.

A presença das mulheres no jogo parece "desnaturar" o rugby. Entretanto, existe o rugby feminino, desta vez sério, oficializado por meio de torneios e até uma Copa do Mundo. A maioria dos rugbymen não o apreciam e expressam com virulência a sua reprovação: "Não vamos falar nisso, isso não existe!" "Elas ficam feiosas, não são mais mulheres." Essa feminização de um jogo que, por muito tempo, era reservado aos homens é percebida como uma anomalia. As esposas de rugbymen também integraram esse discurso reprovador, mesmo que algumas admitam que quiseram jogar rugby quando eram mais jovens. A imprensa também faz pouco caso do rugby feminino omitindo regularmente a comunicação dos resultados de partidas.

No fim deste rápido percurso pelas terras do rugby, algumas conclusões podem ser feitas. Em larga medida, o universo do rugby repete, até caricaturalmente, os estereótipos da definição dos sexos: de um lado, amizade viril, coragem física, disponibilidades para os alegres excessos; e, do outro, duplo brasão de uma feminilidade que hesita entre as imagens freqüentemente associadas da mãe ideal e da amante lasciva. Essa versão é, sem dúvida, a estilização de uma realidade por necessidade mais complexa, mas que dá acesso a um grau de efetividade surpreendente. O rugby, é verdade, bebe nas fontes comuns das representações sociais e, portanto, não há como se espantar com o fato de que um esporte que pretende ser emblematicamente "viril" favoreça as exibições mais esperadas do masculino.

O essencial me parece, contudo, outro: é o fato de um esporte conseguir institucionalizar, em torno de exigências puramente técnicas no início, todos os valores e práticas que lhe permitem formar os homens que requer. Será porque, como gostam de repetir os jornalistas, retrata a "chegada dos tempos modernos" e revela, melhor que qualquer outro esporte, a "parte selvagem" dos verdadeiros machos? Que age, portanto, como revelador (e exutório) de uma violência que se deve de uma maneira ou de outra ter conhecido e dominado para se tornar 
um homem completo? Sem decidir essas questões, podemos, pelo menos, notar que, ao se tornar para seus adeptos um espaço social, um mundo de valores e um estilo de vida, o rugby manifesta seu papel iniciatório muito além da esfera do jogo. São as consonâncias entre suas exigências e modelos culturais compartilhados da formação dos meninos que explicam sua influência sobre os percursos biográficos individuais. Mas, ao mesmo tempo, nesse fundo de harmonia e continuidade, os quadros que impõe aos jogadores atropelam as etapas dos percursos ordinários, a ponto de tornar problemática a relação conjugal. Tanto a figura da "viúva do rugby" como a manutenção anormalmente longa do vínculo com a mãe designam essa anomalia.

(Tradução: Carolina Huang)

\begin{abstract}
La Madre y la Puta - los hombres, las mujeres y el rugby

Resumen: identificando el mundo del rugby como un universo cultural que va mas allá de ser solo una actividad de ocio, vinculada a el aprendizaje de las técnicas del juego, el trabajo tiene como objetivo comprender aspectos del complejo proceso de socialización en que están inseridos aquellos que hacen parte de la familia rugby. Dando atención especial al tercer tiempo y a las actividades que ocurren fuera del campo de juego, intentase comprender el espirito del rugby, en particular en lo que se refiere a las relaciones que los jugadores (hombres) plantean con las mujeres, a lo largo de su carrera deportiva.
\end{abstract}

Palabras claves: Cultura, Deporte, Rugby, Género.

The Mom and the Whore - men, women and rugby

Abstract: identifying the world of rugby as a cultural universe that goes beyond being a leisure activity, bound to the learning of techniques of the game, the work seeks the understanding of the aspects of the complex socialization processes in which are inserted those who are part of the rugby family. Giving special attention to the third time and to the activities that occur outside the game field, the understanding of the rugby spirit is pursuit, particularly to what is concerned to the relations that the players (men) establish with the women during their careers.

Keywords: Culture, Sport, Rugby, Gender. 


\section{Referências}

BOURDIEU, P. Questions de sociologie. Paris, Ed. de Minuit, 1984.

DURKHEIM, E. Les formes élémentaires de la vie religieuse. Paris, PUF, 1985.

FABRE, D. "Les dessous de la mêlée, urnes et mascottes". Autrement, n 25, junho de 1980, p. 121-126.

FABRE, D. "Le garçon enceint". Cahiers de littérature orale, n² 20, 1986, p. 15 39.

GODELIER, M. La production des grands hommes. Paris, Fayard, 1982.

KAUFMANN, J.-C. La trame conjugale, analyse du couple par son linge. Paris, Nathan, 1992.

MAFFESOLI, M. L'ombre de Dionysos, contribution à une sociologie de l'orgie. Paris, Librairie des Méridiens, 1985.

Publicado com a autorização da Revista Terrain. Título original: La maman et la putain. Les hommes, les femmes et le rugby, no 25, p. 13-24, 1995, Ministère de la culture et de la communication, Paris. 